\title{
The Unifying Concept of Illness Behavior
}

\author{
Laura Sirri $^{a}$ Giovanni A. Fava ${ }^{a, c}$ Nicoletta Sonino ${ }^{b, c}$ \\ a Laboratory of Psychosomatics and Clinimetrics, Department of Psychology, University of Bologna, Bologna, \\ and ${ }^{b}$ Department of Statistical Sciences, University of Padova, Padova, Italy; ${ }^{\mathrm{c} D e p a r t m e n t}$ of Psychiatry, \\ State University of New York at Buffalo, Buffalo, N.Y., USA
}

\section{Key Words}

Clinimetrics - Delay in seeking treatment $\cdot$ Frequent attenders $\cdot$ Health care-seeking behavior $\cdot$ Illness behavior $\cdot$ Illness perception $\cdot$ Treatment adherence . Treatment-seeking behavior

\section{Abstract}

The concept of illness behavior was introduced to indicate the ways in which given symptoms may be perceived, evaluated and acted upon at an individual level. Illness behavior may vary greatly according to illness-related, patient-related and doctor-related variables and their complex interactions. In the past decades, important lines of research have been concerned with illness perception, frequent attendance at medical facilities, health care-seeking behavior, treatmentseeking behavior, delay in seeking treatment, and treatment adherence. They have, however, mostly investigated single aspects separately. In this concise review, we suggest that the concept of illness behavior may provide a unifying framework and useful insights to observations and findings that would otherwise remain scattered and unrelated in the medical literature. The wide range of expressions of illness behavior is likely to affect the presentation of any disease and its identification, course and treatment. Assessing illness behavior and devising appropriate responses by health care providers may contribute to the improvement of final outcomes.

Copyright $\odot 2012$ S. Karger AG, Basel

The disease model is still considered the basis for optimal identification of treatments for patients. However, it does not take into consideration that behavioral responses to a medical condition vary widely among subjects facing the same illness. When patient behaviors differ from those expected or recommended by physicians, the greater this discrepancy, the less likely the course of a disease will be predicted solely by biomedical factors [1-3]. Therefore, the disease model cannot explain how recognition, presentation and outcome of a disease may be largely influenced by individual responses to symptoms [4].

The concept of illness behavior provides an explanatory model for clinical phenomena that do not find room in customary taxonomy $[1,2,5]$. It was based on the early work of Sigerist [6] and Parsons [7], who suggested that each disorder cannot be ascribed only to pathophysiological mechanisms but also entails both psychological and social dimensions. In 1929, the Swiss medical historian

\section{KARGER}

Fax +4161306 1234

E-Mail karger@karger.ch

www.karger.com
(C) 2012 S. Karger AG, Basel

0033-3190/13/0822-0074\$38.00/0

Accessible online at: www.karger.com/pps
Laura Sirri, $\mathrm{PhD}$

Department of Psychology

University of Bologna

viale Berti Pichat 5, IT-40127 Bologna (Italy)

E-Mail laurasirri@libero.it 
Henry Sigerist [6] noted how different societies have recognized a specific social status to sick persons characterized by privileges and obligations. Two decades later, the American sociologist Talcott Parsons [7] introduced the term 'sick role', which allows the privilege to sick persons to be exempt from normal responsibilities and social duties, such as work, but includes the obligations to try to get well and, thus, to seek qualified help and to cooperate in recovering. In 1960, Mechanic and Volkart [5] investigated the different ways people react to physical symptoms and the psychosocial and cultural factors affecting such reactions. They defined illness behavior as 'the ways in which given symptoms may be differentially perceived, evaluated, and acted (or not acted) upon by different kinds of persons'. Subsequently, Mechanic [8] provided the following specification: 'Illness behavior refers to the varying ways individuals respond to bodily indications, how they monitor internal states, define and interpret symptoms, make attributions, take remedial actions and utilize various sources of informal and formal care'.

Important lines of research have been concerned with illness perception, health care-seeking behavior, frequent attendance at medical facilities, treatment-seeking behavior, delay in seeking treatment, and treatment adherence. Different investigations, however, dealt with single aspects separately. In this concise review, we suggest that the concept of illness behavior may provide a unifying framework and useful insights. A discussion of issues related to abnormal illness behavior $[4,9,10]$ is beyond the aim of this paper.

\section{Clinical Implications of Illness Behavior}

As stated by Mechanic [8], illness behavior 'shapes the recognition of illness, the selection of patients into care, the degree of compatibility between patient and physician attributions, patterns of health practice and adherence with medical advice, and the course of illness and the treatment process'. The simple fact that, in the presence of certain physical symptoms (e.g. chest pain), some persons immediately seek medical help while others wait a long time before consulting a physician determines the likelihood of early recognition of a life-threatening disease and its prompt treatment and prognosis. Indeed, delay in seeking medical attention may be crucial for the subsequent length of survival of the patient. In a community-based population aged 55 years or older, attention to symptoms suggestive of cancer and intention to seek timely medical help were inadequate on average [11]. In cardiology settings, less than $10 \%$ of patients actively sought professional help as the first response to acute myocardial infarction symptoms, the most frequent initial responses being 'to try to relax' (30.7\% of subjects) and 'to hope or pray symptoms would disappear' (21.7\%) [12]. Prehospital delay was found to significantly predict increased mortality risk [13].

Illness behavior of patients may widely influence health care costs and the workload of physicians. The phenomenon of frequent attendance at primary care health services is emblematic. A great amount of the work of primary-care physicians is concerned with a small percentage of their patients $[14,15]$. However, both subjects who seem to overuse health care services and subjects who tend to self-medicate determine significant repercussions for their own health and public welfare. Community-based studies found that up to $50 \%$ of subjects with severe musculoskeletal pain do not seek medical help [16]. Major consequences include persistence and progression of functional disability, diminished quality of life, increased risk of psychological distress and sleep problems. Furthermore, many individuals who do not seek professional help turn to self-medication, with subsequent risks of complications [16].

The diffusion of chronic medical conditions further highlights how patients themselves determine the course of illness through treatment adherence and daily selfmanagement behaviors, such as glucose testing in diabetes. Inadequate adherence, which also includes overcompliance, may be conceptualized as a variance between treatment-related behaviors displayed by patients and those expected by their physicians $[17,18]$.

Illness behavior may be a source of research bias in clinical trials. Studies on patients recruited in clinical settings may be representative only of those, sometimes the minority, who seek medical help for a certain illness. Thus, findings about medical and psychosocial characteristics as well as response to treatments may pertain to those who adopt the sick role rather than to all the subjects with that illness [8]. Illness behavior may thus affect the recruitment process [19] and account for variations and discrepancies in the results of clinical trials [20]. This is an aspect that deserves attention.

\section{Determinants of IIIness Behavior}

As a major component of clinical encounters, illness behavior involves several variables related to health care efficacy and outcomes (fig. 1). 


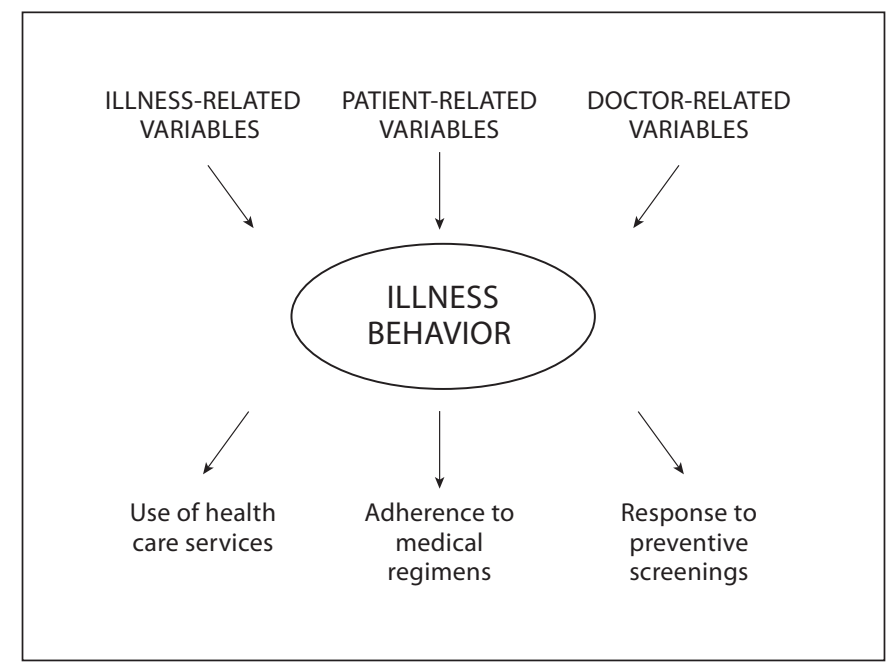

Fig. 1. Main determinants and consequences of illness behavior.

\section{Illness-Related Variables}

According to Mechanic and Volkart [5], the way persons react to an illness may depend on four characteristics of that illness: (1) frequency in the population, (2) familiarity of the symptoms to the average member of the population, (3) predictability of the outcome and (4) degree of threat and loss.

Pain severity and physical disability were frequently reported as reasons for seeking medical help by subjects with chronic pain [16]. Frequency and severity of abdominal pain predicted health care-seeking behavior among subjects with functional gastrointestinal disorders [21].

A rapid onset, together with intensity and persistence of symptoms, were significantly associated with less delay in seeking medical help for chest pain suggestive of a heart attack [22]. On the other hand, subjects with angina could delay seeking help because of an exaggerated sense of control due to previous experiences of chest pain ending with self-help strategies such as resting [22]. Furthermore, diabetic patients may find it more difficult to recognize symptoms of myocardial infarction because of diabetes-related alterations of pain receptors [22, 23].

Persistence of frequent attendance during a two-year follow-up was significantly related both to a higher number of chronic conditions (in particular diabetes) and to medically unexplained symptoms [24].

\section{Patient-Related Variables}

Demographic Variables

Studies examining the relationship between demographic characteristics and illness behavior frequently yielded conflicting results. In subjects with functional gastrointestinal disorders, older age was an independent predictor of health care-seeking behavior. Female gender also seemed to be associated with a higher likelihood of seeking help, but the relationship reached significance only for globus [21].

In subjects with chronic pain, help-seeking behavior seemed to be restrained by masculinity, to increase with aging and to diminish after a certain peak age [16]. Female gender and older age were also significantly associated with frequent attendance in primary care $[14,25]$. Interestingly, older patients, females and racial minorities may be at increased risk of longer prehospital delay after acute myocardial infarction because of 'atypical' presentation of symptoms that make it more difficult to connect symptoms with a heart attack [22]. Among individuals aged 55 years or older, women paid significantly more attention than men to symptoms suggestive of cancer [11].

Cognitive Representations of Illness

Lipowski [26] described eight most frequent meanings given by individuals to their illness: challenge, enemy, punishment, weakness, relief, strategy in interpersonal relations, irreparable loss or damage, and value. The interpretation of symptoms influences the likelihood to adequately recognize an underlying disease and to promptly seek medical care. Cognitive representations of illness may also determine the adoption of preventive behaviors. If a certain disease is considered unavoidable and dependent on factors outside of personal control (e.g. genetics), it is unlikely that preventive measures (e.g. healthy lifestyle and/or regular screening visits) will be adopted. Subjects with chronic pain were less likely to seek medical treatment if they attributed pain to the unavoidable process of aging [27].

According to the self-regulatory model of Leventhal et al. $[28,29]$, representations of subjects of their own illnesses determine the coping behaviors adopted and, consequently, the illness outcome.

Experience of symptoms different from those considered by the individual as typical of a given disease may influence illness behavior, e.g. at the onset of a first myocardial infarction this mismatch was significantly related to longer delay in seeking medical help [30].

Illness perception, which derives from the self-regulatory model [28], is a useful construct to describe the main representations of illness. Dimensions of illness perception were found to significantly predict several features of illness behavior as well as functional recovery [31]. Perception of control over one's own illness was significant- 
ly related to higher attendance at cardiac rehabilitation programs after myocardial infarction [32] and better adherence to medications and self-management recommendations in patients with hypertension [33]. Longitudinal assessment of illness perception after myocardial infarction by the use of patients' drawings found a significant positive relationship between the size of the heart in the drawing and health care utilization [34]. In chronic diseases, many patients engage in a subjective cost-benefit analysis in which beliefs about the benefits of prescribed medications are weighed against their potential adverse effects, and these beliefs are related to adherence to treatment [35].

Psychological Distress and Psychiatric Disorders

Feelings of anxiety and depression may frequently result in both increased attention to and pessimistic interpretation of bodily sensations [36]. Patients who suffer from depression and/or anxiety tend to display more worries about illness, concerns about pain and bodily preoccupations than those who are not depressed or anxious. The treatment of depression and anxiety leads to an improvement in such fears [36-38].

Frequent attenders in general medical practice showed significantly higher levels of psychological distress and more psychiatric disorders than routine attenders [14, 15, 39]. The prevalence of psychiatric comorbidity among frequent attenders was found to vary from 26.7 to $54 \%$, with depressive and somatoform disorders as the most frequent diagnoses $[39,40]$. The reduction of psychological distress through psychotherapy resulted in a significant decrease of health care use and costs $[41,42]$.

In functional gastrointestinal disorders, anxiety and depressive symptoms were significantly higher in health care consulters than nonconsulters, and anxiety independently predicted health care-seeking behavior [21]. In patients with unexplained abdominal pain, worry about abdominal problems significantly predicted increased frequency of medical visits over a 12-month period [43].

In a qualitative synthesis, fear was found to be a major barrier to timely seeking medical help for symptoms suggestive of cancer [44]. Fear was concerned with the consequences of cancer, such as treatment effects, as well as with being labeled as a time waster or a neurotic, and, especially for men, with being embarrassed by physical examinations of sexual or private body areas [44].

\section{Personality}

The role of alexithymia (a personality construct characterized by difficulties in identifying and describing feelings) and emotional inhibition on illness behavior is controversial [45-48]. A positive relationship between alexithymia and frequent attendance at health care services was found, but it was mediated by psychological distress [45] and limited to male gender [46].

Type $\mathrm{D}$ personality (a combination between negative affectivity and social inhibition) was significantly associated with increased health care utilization both in the general population [49] and in cancer survivors [50].

Among the personality dimensions identified by the Big Five model [51], neuroticism was significantly associated with low adherence to medical treatments $[52,53]$.

\section{Childhood Adversities}

Childhood maltreatment, especially sexual abuse, was found to significantly predict frequent health care utilization during adulthood $[54,55]$. Women with both physical and sexual childhood abuse were at particularly high risk for overuse of medical services. They also had higher annual health care costs than women who did not report any abuse [56].

Frequent attendance among general practice patients was significantly related also to other childhood adversities, including absence of confiding relationships and parental antipathy or neglect [57]. Further, attendance at general practitioners was independently predicted by childhood exposure to experiences concerning death and illnesses, such as death of a family member, serious illness in the subject or in a sibling, maternal physical illness, and paternal psychiatric illness [57, 58].

\section{Social Support}

Living alone, unemployment and divorce were significantly related to frequent attendance in general medical practice [14]. Nonetheless, subjects were more likely to seek medical care for symptoms suggestive of severe diseases or chronic pain when encouraged by family members or friends $[16,22,59]$.

Social support is generally associated with better adherence to medical regimens. However, social environment may also exert a negative effect on illness behavior, when significant others provide overoptimistic reassurance and discourage professional help seeking [59]. Subjects were also less likely to adhere to treatments if their families were characterized by conflicts and poor cohesion [60].

Illness behavior may thus ensue from the interaction between the specific challenges of a disease and the social, cultural and psychological background of the patient. 
Table 1. Instruments for assessing illness behavior

\begin{tabular}{|c|c|c|}
\hline Instrument & Author(s) & Description \\
\hline $\begin{array}{l}\text { Illness Behaviour } \\
\text { Questionnaire (IBQ) }\end{array}$ & $\begin{array}{l}\text { Pilowsky and Spence } \\
{[69], 1975}\end{array}$ & $\begin{array}{l}\text { A } 62 \text {-item self-rating questionnaire consisting of } 7 \text { scales: 'general } \\
\text { hypochondriasis', 'disease conviction', 'psychological versus somatic } \\
\text { focusing', 'affective inhibition', 'affective disturbance', 'denial', 'irritability' }\end{array}$ \\
\hline Illness Attitude Scales (IAS) & $\begin{array}{l}\text { Kellner [36], 1986 } \\
\text { Sirri et al. [37], } 2008\end{array}$ & $\begin{array}{l}\text { A } 27 \text {-item self-rating instrument made of } 9 \text { scales: 'worry about illness', } \\
\text { 'concerns about pain', 'health habits', 'hypochondriacal beliefs', } \\
\text { 'thanatophobia', 'disease phobia', 'bodily preoccupations', 'treatment } \\
\text { experience', 'effects of symptoms' }\end{array}$ \\
\hline $\begin{array}{l}\text { Symptom Response } \\
\text { Questionnaire (SRQ) }\end{array}$ & $\begin{array}{l}\text { Egan and Beaton }[70] \\
1987\end{array}$ & $\begin{array}{l}\text { A self-rating instrument which asks subjects to check off what behavioral } \\
\text { responses, among a list of } 12 \text {, they would be likely to display when facing } \\
13 \text { common illness or pain symptoms }\end{array}$ \\
\hline $\begin{array}{l}\text { Illness Cognition } \\
\text { Questionnaire (ICQ) }\end{array}$ & Evers et al. [71], 2001 & $\begin{array}{l}\text { An } 18 \text {-item self-rating instrument made of } 3 \text { scales, each concerning a } \\
\text { specific illness cognition, namely helplessness, acceptance and perceived } \\
\text { benefits }\end{array}$ \\
\hline $\begin{array}{l}\text { Scale for the Assessment of } \\
\text { Illness Behaviour (SAIB) }\end{array}$ & Rief et al. [72], 2003 & $\begin{array}{l}\text { A } 25 \text {-item self-rating instrument with } 5 \text { subscales: 'verification of } \\
\text { diagnosis', 'expression of symptoms', 'medication/treatment', } \\
\text { 'consequences of illness', 'scanning' }\end{array}$ \\
\hline $\begin{array}{l}\text { Behavioural Responses to } \\
\text { Illness Questionnaire (BRIQ) }\end{array}$ & Spence et al. [73], 2005 & $\begin{array}{l}\text { A self-rating instrument examining the frequency with which subjects } \\
\text { display } 21 \text { behaviors in response to the acute phase of an illness. Four } \\
\text { factorial subscales were found: 'all-or-nothing behavior', 'limiting } \\
\text { behavior', 'emotional support seeking', 'practical support seeking' }\end{array}$ \\
\hline $\begin{array}{l}\text { Brief Illness Perception } \\
\text { Questionnaire (Brief IPQ) }\end{array}$ & $\begin{array}{l}\text { Broadbent et al. [74], } \\
2006\end{array}$ & $\begin{array}{l}\text { It includes } 9 \text { self-rating items. The first } 8 \text { items are scored on a continuous } \\
\text { linear scale ranging from } 0 \text { to } 10 \text { and assess: 'consequences', 'timeline', } \\
\text { 'personal control', 'treatment control', 'identity', 'concern', 'illness } \\
\text { comprehensibility', 'emotions'; the last item is an open question which } \\
\text { asks to list the three most important perceived causes of one's own illness }\end{array}$ \\
\hline Illness Cognitions Scale (ICS) & Berk et al. [75], 2012 & $\begin{array}{l}\text { A } 17 \text {-item self-rating scale assessing illness cognitions and behaviors } \\
\text { dealing with investment in the sick role }\end{array}$ \\
\hline $\begin{array}{l}\text { Diagnostic Criteria for } \\
\text { Psychosomatic Research } \\
\text { (DCPR) }\end{array}$ & $\begin{array}{l}\text { Fava et al. [76], } 1995 \\
\text { Porcelli and Sonino } \\
{[77], 2007}\end{array}$ & $\begin{array}{l}\text { A structured interview containing } 58 \text { items for the identification of health } \\
\text { anxiety, disease phobia, thanatophobia, illness denial, functional somatic } \\
\text { symptoms secondary to a psychiatric disorder, persistent somatization, } \\
\text { conversion symptoms, anniversary reaction, type A behavior, irritable } \\
\text { mood, demoralization, alexithymia }\end{array}$ \\
\hline
\end{tabular}

\section{Doctor-Related Variables}

There are different skills of the physician that may enhance the adherence to treatments of the patient, including a clear explanation of the treatment rationale, information about benefits and potential adverse effects, choice of regimens least complex as possible and followup visits $[17,18]$. Indeed, an empathetic and communicative physician-patient relationship was found to be significantly associated with better adherence to medical regimens [61]. Asking patients about their beliefs on illness and its treatment may be crucial to correct inadequate expectations and convictions that may result in poor adherence $[32,33]$. While female gender of the phy- sician was related to shorter patient delay in seeking help for symptoms suggestive of cancer, physician seniority, workload, job satisfaction and burnout did not significantly predict a delay in cancer diagnosis [62].

Kellner [36] reviewed the attitudes of physicians that were found to favorably affect illness behavior in controlled studies concerned with functional medical disorders, which he synthesized in an approach defined as 'explanatory'. It consisted of providing accurate information, reassurance, clarification, repetition, and teaching the principles of selective perception (attention focused on one part of the body makes the patient more aware of sensations in that part of the body than in other parts) 
[36]. In patients undergoing surgery, Egbert et al. [63] found that the provision of instruction, encouragement and suggestions by physicians had a beneficial effect on postoperative pain and length of hospital stay.

Overall, the role of the physician seems to influence and modulate both illness-related and patient-related characteristics.

\section{Assessment}

Patterns of illness behavior may emerge from the medical interview and interaction between patient and physician [64]. Important correlations have been found with psychosocial variables such as life stress, affective disturbances, personality and quality of life, which suggests the need for a broad evaluation [3, 4, 65-68].

When particular situations occur, such as delay in undergoing preventive screening tests or in seeking help, inadequate treatment adherence and overuse of health care services, a more systematic investigation is warranted.

A number of instruments have been developed for identifying the features of illness behavior. The most representative examples are displayed in table 1. Self-rating scales provide dimensional measurements of behavior, perception and cognitive representations of illness [37, 69-75]; they allow a direct appraisal of the patient's subjective views [64-66]. Structured research interviews [65, $76,77]$ make full use of the clinical experience and skills of the interviewer and allow a categorical definition of the phenomena under observation.

A thorough assessment of illness behavior may thus identify issues that can be addressed by the physician. In most cases, problem areas may be amenable to improvement through the provision of medical information and explanation (e.g. in relation to the beliefs of patients about their illness) or managed by structured interventions such as psychotherapy (e.g. in case of psychological distress) [65-68]. As to the high prevalence of medically unexplained symptoms, it has been suggested that it is not that certain disorders lack an explanation, but rather it is our assessment that is inadequate in most of the clinical encounters [65].

\section{Conclusions}

Once the symptoms of a medical disease are experienced by a person, or he/she has been told by a doctor that he/she is ill even if symptoms are absent, this disease-related information gives rise to psychological responses which are likely to influence the course, therapeutic response and outcome of a given illness episode. Illness behavior is one of the factors that demarcate major prognostic and therapeutic differences among patients who otherwise seem to be deceptively similar since they share the same diagnosis. At present, there are several useful tools for assessing illness behavior that can be incorporated in regular practice whenever problems arise. These tools have partial targets and should be part of an assessment strategy that includes the variations of illness behavior and their interactions with life stress, anxiety and depression [4]. For instance, focus on the patient's cognitive representations of disease, if not associated with assessment of other determinants of illness behavior, may yield only partial insights. The concept of illness behavior, as originally formulated $[5,8]$, is more timely than ever and provides a useful framework for the large body of research available, whose results would be otherwise scattered and unrelated in the medical literature. A systematic appraisal of individual illness behavior and the provision of appropriate responses by the physician may contribute to improving medical outcomes.

\section{References}

$>1$ Mechanic D: Social psychologic factors affecting the presentation of bodily complaints. N Engl J Med 1972;286:1132-1139.

$>2$ Engel GL: The biopsychosocial model and medical education. N Engl J Med 1982;306: 802-805.

3 Fava GA, Ruini C, Tomba E, Wise TN: The biopsychosocial factor. Psychother Psychosom 2012;81:1-4.
4 Fava GA, Sonino N, Wise TN (eds): The Psychosomatic Assessment. Strategies to Improve Clinical Practice. Adv Psychosom Med. Basel, Karger, 2012, vol 32.

$\checkmark 5$ Mechanic D, Volkart EH: Illness behavior and medical diagnoses. J Health Hum Behav 1960;1:86-94.

6 Sigerist H: The special position of the sick; in Roemer MI, Henry E (eds): Sigerist on the Sociology of Medicine. New York, MD Publications, 1929, pp 9-22.
7 Parsons T: The Social System. Glencoe, The Free Press, 1951.

8 Mechanic D: Sociological dimensions of illness behavior. Soc Sci Med 1995;41:1207-1216.

9 Pilowsky I: Abnormal Illness Behaviour. Chichester, Wiley, 1997.

10 Sirri L, Fava GA, Wise TN: Psychiatric classification in the setting of medical disease: comparing the clinical value of different proposals. J Psychosom Res 2011;70:493-495. 
-11 van Osch L, Lechner L, Reubsaet A, de Nooijer J, de Vries H: Passive cancer detection and medical help seeking for cancer symptoms: (in)adequate behavior and psychosocial determinants. Eur J Cancer Prev 2007;16:266-274.

12 Dracup K, Moser DK: Beyond sociodemographics: factors influencing the decision to seek treatment for symptoms of acute myocardial infarction. Heart Lung 1997;26:253262.

13 De Luca G, Suryapranata H, Ottervanger JP, Antman EM: Time delay to treatment and mortality in primary angioplasty for acute myocardial infarction: every minute of delay counts. Circulation 2004;109:1223-1225.

-14 Vedsted P, Christensen MB: Frequent attenders in general practice care: a literature review with special reference to methodological considerations. Public Health 2005;119: 118-137.

-15 Ferrari S, Galeazzi GM, Mackinnon A, Rigatelli M: Frequent attenders in primary care: impact of medical, psychiatric and psychosomatic diagnoses. Psychother Psychosom 2008;77:306-314.

16 Cornally N, McCarthy G: Help-seeking behaviour for the treatment of chronic pain. $\mathrm{Br}$ J Community Nurs 2011;16:90-98.

17 Osterberg L, Blaschke T: Adherence to medication. N Engl J Med 2005;353:487-497.

18 Roumie CL: The doughnut hole: it's about medication adherence. Ann Intern Med 2012;156:834-835.

-19 Arfken CL, Balon R: Declining participation in research studies. Psychother Psychosom 2011;80:325-328.

20 Tomba E: Nowhere patients. Psychother Psychosom 2012;81:69-72.

21 Koloski NA, Talley NJ, Boyce PM: Epidemiology and health care seeking in the functional GI disorders: a population-based study. Am J Gastroenterol 2002;97:2290-2299.

22 Khraim FM, Carey MG: Predictors of prehospital delay among patients with acute myocardial infarction. Patient Educ Couns 2009;75:155-161.

23 DeVon HA, Penckofer S, Larimer K: The association of diabetes and older age with the absence of chest pain during acute coronary syndromes. West J Nurs Res 2008;30:130144.

-24 Smits FT, Brouwer HJ, ter Riet G, van Weert HC: Epidemiology of frequent attenders: a 3-year historic cohort study comparing attendance, morbidity and prescriptions of one-year and persistent frequent attenders. BMC Public Health 2009;9:36.

-25 Koskela TH, Ryynanen OP, Soini EJ: Risk factors for persistent frequent use of the primary health care services among frequent attenders: a Bayesian approach. Scand J Prim Health Care 2010;28:55-61.

-26 Lipowski ZJ: Physical illness, the individual and the coping processes. Psychiatry Med 1970;1:91-102.
27 Sanders C, Donovan JL, Dieppe PA: Unmet need for joint replacement: a qualitative investigation of barriers to treatment among individuals with severe pain and disability of the hip and knee. Rheumatology 2004;43: 353-357.

28 Leventhal H, Meyer D, Nerenz D: The common sense representation of illness danger; in Rachman S (ed): Medical Psychology, vol 2. New York, Pergamon Press, 1980, pp 7-30.

29 Hagger MS, Orbell S: A meta-analytic review of the common-sense model of illness representations. Psychol Health 2003;18:141-184.

30 Horne R, James D, Petrie K, Weinman J, Vincent R: Patients' interpretation of symptoms as a cause of delay in reaching hospital during acute myocardial infarction. Heart 2000; 83:388-393.

31 Petrie KJ, Jago LA, Devcich DA: The role of illness perceptions in patients with medical conditions. Curr Opin Psychiatry 2007;20: 163-167.

32 French DP, Cooper A, Weinman J: Illness perceptions predict attendance at cardiac rehabilitation following acute myocardial infarction: a systematic review with metaanalysis. J Psychosom Res 2006;61:757-767.

33 Chen SL, Tsai JC, Chou KR: Illness perceptions and adherence to therapeutic regimens among patients with hypertension: a structural modeling approach. Int J Nurs Stud 2011;48:235-245.

-34 Broadbent E, Ellis CJ, Gamble G, Petrie KJ: Changes in patient drawings of the heart identify slow recovery after myocardial infarction. Psychosom Med 2006;68:910-913.

35 Horne R, Weinman J: Patients' beliefs about prescribed medicines and their role in adherence to treatment in chronic physical illness. J Psychosom Res 1999;47:555-567.

36 Kellner R: Somatization and Hypochondriasis. New York, Praeger, 1986.

37 Sirri L, Grandi S, Fava GA: The Illness Attitude Scales. A clinimetric index for assessing hypochondriacal fears and beliefs. Psychother Psychosom 2008;77:337-350.

38 Nakao M, Shinozaki Y, Ahern DK, Barsky AJ: Anxiety as a predictor of improvements in somatic symptoms and health anxiety associated with cognitive-behavioral intervention in hypochondriasis. Psychother Psychosom 2011;80:151-158.

39 Gili M, Luciano JV, Serrano MJ, Jiménez R, Bauza N, Roca M: Mental disorders among frequent attenders in primary care: a comparison with routine attenders. J Nerv Ment Dis 2011;199:744-749.

40 Karlsson H, Lehtinen V, Joukamaa M: Psychiatric morbidity among frequent attender patients in primary care. Gen Hosp Psychiatry 1995;17:19-25.

41 Creed F, Fernandes L, Guthrie E, Palmer S, Ratcliffe J, Read N, Rigby C, Thompson D, Tomenson B: The cost-effectiveness of psychotherapy and paroxetine for severe irritable bowel syndrome. Gastroenterology 2003; 124:303-317.
42 Konnopka A, Schaefert R, Heinrich S, Kaufman C, Luppa M, Herzog W, Konig HH: Economics of medically unexplained symptoms: a systematic review of the literature. Psychother Psychosom 2012;81:265-275.

-43 Koloski NA, Talley NJ, Boyce PM: Does psychological distress modulate functional gastrointestinal symptoms and health care seeking? A prospective, community cohort study. Am J Gastroenterol 2003;98:789-797.

44 Smith LK, Pope C, Botha JL: Patients' helpseeking experiences and delay in cancer presentation: a qualitative synthesis. Lancet 2005;366:825-831.

45 Joukamaa M, Karlsson H, Sholman B Lehtinen V: Alexithymia and psychological distress among frequent attendance patients in health care. Psychother Psychosom 1996; 65:199-202.

-46 Jyväsjärvi S, Joukamaa M, Väisänen E, Larivaara P, Kivelä SL, Keinänen-Kiukaanniemi S: Alexithymia, hypochondriacal beliefs, and psychological distress among frequent attenders in primary health care. Compr Psychiatry 1999;40:292-298.

47 Lumley MA, Neely LC, Burger AJ: The assessment of alexithymia in medical settings: implications for understanding and treating health problems. J Pers Assess 2007;89:230246

48 Grandi S, Sirri L, Wise TN, Tossani E, Fava GA: Kellner's Emotional Inhibition Scale: a clinimetric approach to alexithymia research. Psychother Psychosom 2011;80:335-344.

-49 Michal M, Wiltink J, Grande G, Beutel ME, Brähler E: Type D personality is independently associated with major psychosocial stressors and increased health care utilization in the general population. J Affect Disord 2011;134:396-403.

50 Mols F, Oerlemans S, Denollet J, Roukema JA, van de Poll-Franse LV: Type D personality is associated with increased comorbidity burden and health care utilization among 3,080 cancer survivors. Gen Hosp Psychiatry 2012;34:352-359.

51 McCrae RR, Costa PT Jr: Updating Norman's 'Adequate Taxonomy': intelligence and personality dimensions in natural language and in questionnaires. J Pers Soc Psychol 1985;49:710-721.

52 Axelsson M, Brink E, Lundgren J, Lötvall J: The influence of personality traits on reported adherence to medication in individuals with chronic disease: an epidemiological study in West Sweden. PLoS One 2011;6: e18241.

53 Jerant A, Chapman B, Duberstein P, Robbins J, Franks P: Personality and medication nonadherence among older adults enrolled in a six-year trial. Br J Health Psychol 2011;16: 151-169.

54 Arnow BA: Relationships between childhood maltreatment, adult health and psychiatric outcomes, and medical utilization. J Clin Psychiatry 2004;65(suppl 12):10-15. 
-55 Applebaum J, Nemets B, Kaplan Z, Witztum E, Belmaker RH: Prevalence of history of childhood sexual abuse in consecutive hospital admissions of women with psychotic diagnosis in Israel: a preliminary report. Psychother Psychosom 2012;81:318-319.

-56 Bonomi AE, Anderson ML, Rivara FP, Cannon EA, Fishman PA, Carrell D, Reid RJ, Thompson RS: Health care utilization and costs associated with childhood abuse. J Gen Intern Med 2008;23:294-299.

-57 Kapur N, Hunt I, Macfarlane G, McBeth J, Creed F: Childhood experience and health care use in adulthood: nested case-control study. Br J Psychiatry 2004;185:134-139.

-58 Porcelli P, Fava GA, Rafanelli C, Bellomo A, Grandi S, Grassi L, Pasquini P, Picardi A, Quartesan R, Rigatelli M, Sonino N: Anniversary reactions in medical patients. J Nery Ment Dis 2012;200:603-606.

59 Howell DA, Smith AG, Roman E: Help-seeking behaviour in patients with lymphoma. Eur J Cancer Care 2008;17:394-403.

-60 DiMatteo MR: Social support and patient adherence to medical treatment: a metaanalysis. Health Psychol 2004;23:207-218.

61 Beck RS, Daughtridge R, Sloane PD: Physician-patient communication in the primary care office: a systematic review. J Am Board Fam Pract 2002;15:25-38.
62 Hansen RP, Vedsted P, Sokolowski I, Sønder gaard J, Olesen F: General practitioner characteristics and delay in cancer diagnosis. A population-based cohort study. BMC Fam Pract 2011;12:100.

63 Egbert LD, Battit GE, Welch CE, Bartlett MK: Reduction of postoperative pain by encouragement and instruction of patients. A study of doctor-patient rapport. N Engl J Med 1964;270:825-827.

64 Bardes CL: Defining 'patient-centered medicine’. N Engl J Med 2012;366:782-783.

65 Fava GA, Tomba E, Sonino N: Clinimetrics: the science of clinical measurements. Int J Clin Pract 2012;66:11-15.

66 Tomba E, Bech P: Clinimetrics and clinical psychometrics: macro- and micro-analysis. Psychother Psychosom 2012;81:333-343.

67 Tomba E, Offidani E: A clinimetric evaluation of allostatic overload in the general population. Psychother Psychosom 2012;81: 378-379.

68 Sonino N, Peruzzi P: A psychoneuroendocrinology service. Psychother Psychosom 2009; 78:346-351.

69 Pilowsky I, Spence ND: Patterns of illness behaviour in patients with intractable pain. J Psychosom Res 1975;19:279-287.

70 Egan KJ, Beaton R: Response to symptoms in healthy, low utilizers of the health care system. J Psychosom Res 1987;31:11-21.
71 Evers AW, Kraaimaat FW, van Lankveld W, Jongen PJ, Jacobs JW, Bijlsma JW: Beyond unfavorable thinking: the illness cognition questionnaire for chronic diseases. J Consult Clin Psychol 2001;69:1026-1036.

72 Rief W, Ihle D, Pilger F: A new approach to assess illness behaviour. J Psychosom Res 2003;54:405-414.

73 Spence M, Moss-Morris R, Chalder T: The Behavioural Responses to Illness Questionnaire (BRIQ): a new predictive measure of medically unexplained symptoms following acute infection. Psychol Med 2005;35:583593.

74 Broadbent E, Petrie KJ, Main J, Weinman J: The Brief Illness Perception Questionnaire. J Psychosom Res 2006;60:631-637.

75 Berk M, Berk L, Dodd S, Jacka FN, Fitzgerald PB, de Castella AR, Filia S, Filia K, Kulkarni J, Jackson HJ, Stafford L: Psychometric properties of a scale to measure investment in the sick role: the Illness Cognitions Scale. J Eval Clin Pract 2012;18:360-364.

76 Fava GA, Freyberger HJ, Bech P, Christodoulou G, Sensky T, Theorell T, Wise TN: Diagnostic criteria for use in psychosomatic research. Psychother Psychosom 1995;63:1-8.

77 Porcelli P, Sonino N (eds): Psychological Factors Affecting Medical Conditions. A New Classification for DSM-V. Adv Psychosom Med. Basel, Karger, 2007, vol 28. 